LA METAMORFOSIS RITUAL:

\title{
la identidad religiosa en la Amazonia
}

\author{
JEAn-Pierre GoUlard \\ Doctor EN ANTROPOLOGÍA \\ Miembro de Le Sentiment du Corps dans les Cultures et Leurs Natures \\ Equipo de InVEstigación del Laboratoire d’Anthropologie Social, París \\ jean-pierre.goulard@wanadoo.fr
}

\begin{abstract}
Resumen
as sociedades indígenas han conocido muchos cambios a lo largo de su historia, Lespecialmente desde el siglo xIx. Sus relaciones con el exterior, sobre todo con el mundo de los "blancos", los han llevado a adoptar estrategias propias con las cuales han logrado sobrevivir. En este documento se analizan algunos aspectos religiosos inducidos por los movimientos proféticos que prevalecen entre los tikuna grupo étnico amazónico, y que han determinado las opciones escogidas por este pueblo. A través de tal eje, el autor muestra cómo, a pesar de lo vivido por el grupo étnico, ha sido posible mantener un sistema de creencias que sigue en diálogo con la vida de su sociedad. Entonces, se propone la hipótesis de que se puede entender que este sistema perdura y se fundamenta en invariantes socioculturales que se entienden a través del filtro de la metamorfosis ritual, que les permite a los tikuna conservar y reivindicar su identidad étnica.
\end{abstract}

Palabras Clave: tikuna, mesianismo, profetismo, chamanismo, invariantes.

\section{The Ritual Metamorphosis: Religious Identity in the Amazonian Area}

\begin{abstract}
The indigenous societies have undergone many changes, and more intensely so since the 19th century. Their relations with the outside, of which the white world is the main part, have led them to adopt strategies in order to survive. In this work, the author analyzes how certain religious aspects inferred by the prophetic movements which prevail among the Tikuna, an Amazonian ethnic group, have determined and directed the changes inside this society. Through the choice of such an approach, the researcher shows that, in spite of what the members of the ethnic group have experienced, it has been possible for the Tikuna to preserve a system of faiths in constant dialogue with the life of the society. It is then relevant to consider that such a situation continues because its foundations consist in sociocultural invariants which can be discerned through the filter of a ritual metamorphosis, an operation which allows the members of this group to assert and claim their ethnic identity.
\end{abstract}

KEYWORDS: tikuna, messianism, prophetism, shamanism, invariants.

Revista Colombiana de Antropología

Volumen 48 (2), julio-diciembre 20I2, pp. I5-37 


\section{INTRODUCCIÓN ${ }^{1}$}

$\mathrm{n}$ el interior de cada sociedad surgen con frecuencia movimientos de diversos tipos en respuesta a eventos sociales, políticos -y económicos, y quienes participan en ellos deben acudir a sus propias especificidades para reaccionar a tales fenómenos. En estos contextos, pueden aparecer actores cuyos discursos concuerdan con las aspiraciones de la gente y que inducen a cambios diversos; son iniciado-

I Tengo que agradecerle a Óscar Iván García R., quien ha tenido una gran paciencia para discutir y revisar mi texto, y cuyo aporte ha sido importante para establecer su versión definitiva; a Mara Bermúdez, por su atención en la escritura; y a María Teresa Salcedo, por su seguimiento en la redacción final. res que proponen la adopción de nuevas orientaciones para los espacios sociales. Entre un abanico de posibilidades, nos interesaremos por la oferta religiosa, particularmente aquella que se distingue por una característica concreta: la presencia de un iniciador que sostiene un mensaje que coincide o concuerda con las esperanzas de sus oyentes y se propaga en un espacio geográfico determinado. Tal iniciador es visto como un mensajero al cual sus seguidores se adhieren, individual o colectivamente, de forma inmediata y con una duración variable. A estos fenómenos se los puede reconocer como movimientos mesiánicos.

En las sociedades que conocen tales movimientos, estos pueden sucederse en un proceso repetitivo en el que uno reemplaza a otro, pero también puede ocurrir que algunos de ellos coexistan al mismo tiempo, de manera que conformen un proceso extensivo. Se reconoce entonces una constante profética, es decir que los adeptos proceden a una renovación permanente de su adhesión religiosa, nunca pensada como una ruptura, a partir de una figura que es una "deidad”. Mi hipótesis es que tal adhesión se fundamenta en un esquema cultural, hecho de invariables, esto es, de rasgos prestados de la mitología que perduran de un movimiento a otro. Así, un análisis comparativo de la aceptación de tales movimientos por una sociedad determinada podría facilitar la elaboración de una gramática de las representaciones simbólicas, herramienta que permitiría comprender mejor el profetismo. Mi propósito es basarme en algunas de las relaciones que están en juego en la sociedad tikuna para mostrar cómo la permanencia del sujeto es el horizonte cultural de la búsqueda de sentido en 
el cual se proyectan infinitamente sus miembros, más allá de la consideración de su adhesión del momento.

Mi interés sobre esta problemática nació después del estudio de esta sociedad, en la cual tuve la oportunidad de desarrollar la parte más importante de mi trabajo de campo. Esta experiencia me permitió reconocer rasgos culturales que dejan ver las bases de una adhesión profética colectiva, permanente y moldeada por el contexto. Mi interés es confirmar si esta potencialidad se corresponde con un modelo conceptual único por ser verificable en diversos movimientos proféticos.

Los tikuna son un grupo de al menos cincuenta mil personas distribuidas en las inmediaciones de las fronteras de Colombia, Perú y Brasil. Se trata de un grupo que comparte una lengua tonal común con tres dialectos (Santos 2005). A partir del siglo XIX un número importante de estos indígenas se mudaron de la zona interfluvial hacia las riberas del río Amazonas, y pasaron de habitar en viviendas multifamiliares (malokas) a residir en casas monofamiliares reagrupadas en caseríos. Dejaron de ser cazadores para convertirse en pescadores, pero a pesar de tal desplazamiento continuaron practicando la horticultura de tumba y quema. Pese a la importancia de la migración, unos miles de entre ellos viven todavía en el interfluvio y algunas centenas en malokas.

Durante el siglo xx se conocieron al menos diez movimientos religiosos que se pueden leer en una perspectiva profética: el movimiento I (fin del siglo XIX) surgió con las profecías de una mujer joven (Nimuendaju 1952, 138). El movimiento II (diez años después) sobrevino tras las visiones de un hombre conocido como Aureliano (138). El movimiento III (1932) se conformó después de que una mujer que tuvo una visión incentivó a la gente a reagruparse a la espera de la llegada de Deus (Vinhas de Queiroz 1963, 45-46). El movimiento Iv (1938-1939) surgió con el anuncio de una inundación próxima por parte de una señora informada por un jaguar (36). El movimiento v (1940-1941) llevó a los indígenas a reunirse después de los encuentros de un joven, Nhorane, con Tekukira, hijo de Ipi, el menor de los gemelos míticos (Nimuendaju 1952, 138-139). El movimiento VI (1946) siguió al encuentro de un indígena, Aprigio, con un hombre que le anunció la llegada cercana de un diluvio de agua caliente (Vinhas de Queiroz 1963, 47-50). Al movimiento vII 
(1956-1960) lo precedió el anuncio de un chamán, Ciriaco, acerca de la llegada de un barco con mercancías y de la cercanía de una ciudad encantada (51-53). El movimiento vIII (desde 1972 hasta hoy) se inició con la bajada, por el Amazonas, de un hombre llamado José da Cruz. El movimiento Ix (desde 1953 hasta hoy) empezó con la llegada de una pareja misionera norteamericana a Brasil, de donde se mudó a Perú y formó una comunidad con discípulos. Después, se formaron otras comunidades basadas en esta misma ideología evangelista, pero se consideran en total autonomía una de la otra, sin relación particular entre ellas, y cada una tiene su historia propia. El movimiento x (desde 1968 hasta hoy) fue iniciado por un cura católico que reunió en un mismo lugar a familias esparcidas en las riberas de un afluente de la orilla colombiana del Amazonas, quien ha sido considerado como el fundador.

2 Fritz había iniciado numerosos reagrupamientos de miembros de varios grupos étnicos ribereños e interfluviales en sitios llamados reducciones, o sea misiones en las cuales se trataba de bautizarlos. Tres siglos después, similares desplazamientos monoétnicos se observan en todos los movimientos conocidos por los tikuna desde el comienzo del siglo xx (infra).

3 Por ejemplo, el uso de las máscaras durante la celebración de los rituales es común entre grupos étnicos vecinos, entre ellos los tikuna y los juri-yuri, que tenían contactos entre sí desde antes de su establecimiento en las riberas del río Amazonas (Goulard y Montès 2012).
Pero la región del medio Amazonas, donde viven hoy en día los tikuna, ha conocido desde la Conquista diversos movimientos de carácter religioso. Podemos mencionar entre ellos el impulso mesiánico suscitado por Samuel Fritz, misionero jesuita que animó durante varios años (fin del siglo xvII y comienzos del siglo xvIII) muchas misionesreducciones $^{2}$ de la provincia de Maynas. Después de haber sido detenido durante dos años por los portugueses en el actual territorio de Brasil, su regreso ocasionó reagrupamientos de poblaciones en cada lugar donde se detenía y era considerado como un profeta. Otros datos dejan pensar que los tikuna y sus vecinos, moradores del interfluvio, conocían los impulsos proféticos de los arawak (al norte) y de los tupí (al sur).

Se puede pensar que los tikuna, en sus vicisitudes, habrían recibido influencias de diversa índole: cultural, dogmática, religiosa, etc., de parte de estos poderosos grupos, que habrían introducido nuevos modelos de pensamiento en la región. Aunque es difícil conocerlos en detalle, el influjo religioso ha sido compartido, de una manera u otra, así como otros elementos culturales $^{3}$. Varios estudios recientes permiten conocer de cerca 
problemáticas similares en diferentes partes de la Amazonia. Se sabe que el fenómeno del mesianismo ha tenido una extensión más amplia que la que se conoce actualmente - ver, por ejemplo, Wright $(1992,2004)$, para el conjunto arawak-. Pero fue A. Métraux (1928) el primero en reflexionar sobre el mesianismo, a partir del caso tupí-guaraní; no obstante, a pesar de la lucidez y profundidad de sus investigaciones, este autor deja pendiente un conjunto de preguntas implícitas, entre ellas: ¿qué tipos de mesianismos tienen lugar en estos contextos?, ¿puede hablarse o no de un mesianismo endógeno en contraste con un mesianismo exógeno?, y si han subsistido paralelamente, ¿es posible que se hayan fundido? El material tikuna expuesto enseguida participa de esta discusión, y constituye un aporte a la búsqueda de respuestas a estos interrogantes.

\section{Contexto}

p

ara entender la situación actual de los tikuna conviene recordar su recorrido a través del cuadro idéel que prevalece entre ellos. Por cuadro idéel se entiende "el conjunto de las representaciones que se han hecho y que se hacen de la naturaleza y del origen del universo que los rodea, de los seres que lo pueblan o supuestamente lo pueblan y de los humanos mismos pensados en sus diferencias y/o sus representaciones" (Godelier 2007, 38).

Según los tikuna no hay un origen, un inicio de la creación, sino un tiempo primero, muchas veces expresado por la locución en este tiempo. Ya estaban presentes "seres vivos" du-ũgü en el "cosmos" na-ane, término polisémico que expresa a la vez el tiempo, el espacio... Era inestable, literalmente: no estaba "maduro". Después de una serie de actuaciones, los gemelos míticos, Joi e Ipi, nacidos de las rodillas de su padre, Ngutapa, buscaron asegurar su estabilidad. En el río primordial atraparon peces, que al tocar la tierra firme se transformaron en "seres" dotados de una apariencia humana, población que ha sido la primera "generación”, la de los "primeros pescados" pogüta. Por no saber, cometieron en seguida relaciones incestuosas y, en consecuencia, desaparecieron en un primer cataclismo. El mayor de los gemelos favoreció entonces el establecimiento de un sistema clánico que permitió imponer reglas matrimoniales entre los seres de la 
“generación” siguiente. Fue después que el na-ane se estabilizó; desde ese momento, el mundo está poblado por diferentes clases de seres $d u$-ũgü, entre los cuales están los “du-ũgü-verdaderos”, $d u-\tilde{u} g u ̈-\tilde{u} c h i$, los tikuna. Los grandes vegetales, la mayoría de los animales y otras entidades que han perdido su apariencia humana por razones diferentes (Goulard, 2009) son igualmente $d u$-ũgü.

Más tarde, en el transcurso de su reclusión, al tener su primera menstruación, una joven no supo respetar la norma que le prohibía tener contacto con los de su medio ambiente y le habló al espíritu Vejez, quien la llamaba a través la pared de su celda. Vejez intercambió con ella su piel, y desde ese momento los tikuna conocen el estado mortal, son yunatü, mientras los que se habían quedado al lado

4 Término cuya raíz, ü-ü, refiere al fuego y/o al hacer, $y$-ne, al cuerpo. Se traduce entonces por cuerpo-fuego y/o hacer-cuerpo. Se puede entender el primer significado como que estos seres viven en un medio frío, de ambiente selvático, del que salen pocas veces, y el segundo significado se refiere a un estado completo. de Joi, el mayor de los gemelos, y otros más que se encuentran todavía hoy en día en el medio ambiente cercano han conservado su estado inicial, el de la inmortalidad, ü-üne ${ }^{4}$.

Los seres ü-üne contrastan con los seres mortales, yunatü, que son los tikuna. Los primeros viven en un territorio frío, la selva, y los segundos en uno que es caliente debido a la actividad propia de los mortales. Durante sus rituales unos y otros se juntan: se crea un periodo atemporal de conjunción que debe permitirles a los mortales acompañar a los inmortales una vez se termina el evento. A lo largo de todo el ritual, cualquiera que sea, esto se recuerda sin cesar en los cantos.

Este cuadro de la creación ofrece los medios y los procesos que hacen que "las realidades idéelles se encarnen a la vez en realidades materiales y en prácticas que les dan un modo de existencia concreto, visible, social" (Godelier 2007, 38): constituyen el campo simbólico de la sociedad con su puesta en acto. Si la pérdida del estado de la inmortalidad es siempre recordada, al mismo tiempo todas las personas que asisten a una celebración tienen la posibilidad de recuperarlo. Sin embargo, para alcanzarlo tienen que someterse a ciertas condiciones, entre las cuales están las reglas de socialidad, o si no buscar, por lo menos, que la sociedad se mantenga en su estado actual, para que no desaparezca a causa de un cataclismo siempre latente. De verdad, todos los actores son conscientes de pertenecer a un ciclo; saben 
que las capas geológicas del subsuelo demuestran la existencia de las generaciones anteriores, las cuales desaparecieron por no haber tomado en cuenta las normas impuestas. Los colores de estas capas, que se ven en cualquier barranco, son la prueba de los eventos ocurridos: las de color gris claro son consecutivas a un diluvio, las de color negro, a un incendio. La generación actual teme experimentar el mismo destino debido a las faltas intraétnicas (incestos) y extraétnicas (guerras y conflictos), que parecen cada día más numerosas. Esta percepción imaginaria del Sí, voluntad expresa de escapar de una desaparición funesta, conforma, hoy en día, un horizonte cultural amazónico, en la medida en que los conjuntos étnicos vecinos, los tupí, los arawak y otros, incluidos unos grupos mestizos, comparten un temor similar. Así, entre los tikuna, con la excepción del recorrido del renunciante (infra), opción masculina e individual (Goulard, 2009), el tema del acceso a la inmortalidad vale ante todo en

5 La inmortalidad, entre los tikuna, se diferencia de la cristiana en la medida en que sí comprende al ser completo, con todos sus componentes, y se piensa ante todo de manera colectiva. un cuadro colectivo ${ }^{5}$.

\section{LÍDER PROFÉTICO}

$A \begin{aligned} & l \text { final del siglo xix tuvo lugar el primer movimiento religioso } \\ & \text { conocido entre los tikuna, al que siguieron muchos otros hasta } \\ & \text { el día de hoy. Cada uno ha sido iniciado por un personaje que }\end{aligned}$ lleva un discurso escatológico y propone la salvación, o sea la recuperación del estado ü-üne. Cuando su propuesta es aceptada, puede ser percibido como un mesías, un profeta, un fundador, uno mandado por dios, o como el descendiente directo de un héroe mítico, su encarnación o incluso el héroe mismo. Esta situación puede resultar difícil de comprender, pero si la relación carnal es significada de manera que no pueda ponerse en duda, es reconocido como un mensajero que restituye la Palabra y que, tarde o temprano, se confundirá con el héroe mítico que le ha comunicado el mensaje espiritual.

El profeta no tiene un perfil único: puede ser un chamán, un joven, una mujer —entre los ejemplos citados se cuentan tres (movimientos I, II y v)—o un hombre extranjero (VIII, IX y x). Estos personajes (al menos los hombres, dado que hay poca 
información a propósito de las mujeres) son fácilmente llamados "nuestro padre", tanatü. Según los movimientos, son asociados a Joi o Ipi, Ngutapa o también a "Dios" o Tupana. Si Joi, Ipi y Ngutapa son nombres de héroes mitológicos, Tupana resulta de la tikunaización de la palabra tupí tupa $\tilde{a}^{6}$, que hace referencia al trueno, que los misioneros, durante la Conquista, asociaron a Dios $^{7}$. Cualquiera que sea el término usado, se trata siempre del mismo héroe escatológico cuya denominación cambia según el contexto: el héroe conserva el mismo contenido, aunque aporta transformaciones adaptativas, hasta ser reivindicado como propio y exclusivo. La permanencia de tal filiación atestigua

Métraux (1928) anota que los autores de las primeras crónicas "interpretan ese nombre [Tupan] como un término que significa 'cosa sagrada, misteriosa y excelente' y que habría sido especialmente aplicado al trueno y a los relámpagos, en los cuales los indios habrían visto la manifestación de una fuerza invisible". Según el mismo autor, "Tupan, lejos de ser una simple noción que implica la idea de sagrado, es una clase de genio o de demonio a quien no se rinde ningún culto [...]" (52).

7 Sin duda, no hay que ver este proceso solamente desde el punto de vista lingüístico. Los indígenas mismos adaptan y en consecuencia adoptan la terminología propuesta porque su panteón tiene entidades cuyas cualidades son cercanas a las que proponen los movimientos proféticos. De esta manera, existe un préstamo consentido y consciente $y$, hasta cierto punto, simétrico.

8 Proceso conocido entre los tupí, quienes creían en "la reencarnación del alma de sus ancestros" (Métraux 1928, 103).

9 El termino aegakü ("principio vital"-"palabra""sujeto") se refiere a la autoridad, algo como una nebulosa de los blancos, el poder políitico, como el gobierno nacional que los domina, y sirve para aceptar a su representante como su encarnación. la asociación verdadera con la deidad. Como ya se ha dicho, el profeta integra esta relación desde el momento en que ha sido aceptado, lo que fortalece su dicho. José da Cruz, profeta del movimiento vIII, insiste en ser la encarnación ${ }^{8}$ de la deidad: él ha sido "mandado por Dios", y en otros momentos es Dios (Oro 1989, 85). En ciertas ocasiones, él les pregunta a los presentes si lo ven o lo reconocen como Joi, el mayor de los gemelos míticos. Tal relación tiene un carácter espiritual, pero ante todo es la prueba de una filiación in caro. Del mismo modo, uno de sus seguidores le preguntaba al pastor americano que había iniciado el movimiento Ix si era Dios, lo que confirma el modelo de asimilación del líder religioso con las

deidades. Esta percepción se encuentra en otros campos: así, los representantes de la autoridad, "lo que manda" aegakü9, se inscriben en un esquema similar. Eso se debe a que los tikuna asocian fácilmente a los blancos korigü con la inmortalidad: ellos no conocen la muerte por ser numerosos y viven en ciudades i-ane (infra) con luz eléctrica, una aspiración formulada en varios movimientos. Así, el mensaje presenta correspondencias con lo que se espera. 
A partir de ese momento, su aceptación tiene lugar por medio de diferentes estrategias, una de las cuales es la capilaridad; en este caso, el testimonio de un testigo que ha escuchado al profeta o a quien se le han contado las proezas de este es suficiente para que sus oyentes se adhieran a su movimiento.

Lo anterior no impide que puedan aparecer "falsos" profetas. Los denunciados como tales son personajes cuyos discursos tienen propuestas que son consideradas falaces o inaudibles ${ }^{10}$. Como ya se ha dicho, la primera característica de un discurso profético es que su contenido corresponda a la esperanza colectiva. Sin este requisito, tal mensajero no puede ser entendido, menos aceptado, y se lo asocia a una encarnación del diablo.

10 Desde 1997 la sociedad tikuna y los habitantes de la región del medio Amazonas se enfrentan a la llegada masiva de un conjunto de migrantes religiosos conocidos como israelitas; se trata de un grupo de más de quince mil personas, procedente de los Andes (Perú y Colombia), que siguen las directivas de su profeta, quien les ha presentado la Amazonia como la tierra prometida. Sin embargo, sus propuestas no han sido aceptadas por la población indígena de la región, dado que no presentan ninguna correspondencia con sus esperanzas. Este movimiento muestra un sectarismo ideológico de carácter andino que no tolera de ninguna manera la fluidez de las relaciones que prevalecen en el contexto amazónico. No obstante, este movimiento ha tenido cierto impacto en otros campos, por ejemplo, al participar de la difusión del concepto de tierra-madre, que estaba ausente hasta el momento en las tierras bajas pero que es frecuentemente usado por otros actores, entre los que se cuentan ciertas ONG ambientalistas. Es un término usado, ante todo, por los adeptos de la ideología de la Nueva Era.

Una vez reconocidos, los profetas pasan a ser facilitadores, por catalizar las esperanzas - estas no son siempre expresadas, pero sí sentidas- del colectivo mismo. De cara a la población, constituyen la proyección social de la búsqueda de la salvación. Desde el momento en que son reconocidos se convierten en detentadores y portadores de un proyecto de sociedad. Su discurso busca formular una totalidad, con propuestas que determinan sectores diversos: económico, político, educativo para los más recientes, etc. Este discurso, fundamentado por lo religioso, sintetiza y define una esperanza, mucho tiempo difundida, en la cual se ofrece una opción o una salida a la crisis.

¿Los profetas son personajes dotados de carisma? Es difícil afirmarlo, es mejor exponer algunas de sus características. Un denominador común entre ellos es que son percibidos como impregnados del principio vital de la entidad que los manda, lo cual es prueba de la Palabra transmitida. Otra característica compartida, al menos por los movimientos vIII a x, es su externalidad: el que el pastor americano José da Cruz y el cura católico sean extranjeros entre los tikuna le confiere una unción a lo 
que proponen, y al mismo tiempo hace de ellos figuras que les permiten a los indígenas acercarse a los blancos y "civilizarse". Esta situación es el revés de lo que sucedió en los primeros movimientos, en los que la Palabra proponía recuperar un estado anterior abandonado. Sin embargo, en el contexto contemporáneo, unos y otros participan del mismo na-ane, aunque sus límites se han alargado, hasta incluir un "más allá" del que se sabe por los medios de comunicación (televisión, cine, radio) o que algunos han conocido por su estadía (infra) en otro lugar donde han visto o experimentado técnicas y modos de vida de los cuales pueden dar testimonio.

Por otra parte, no hay duda de que la Palabra de los profetas contiene inflexiones cristianas, aunque las envuelve en un discurso que toma en cuenta los habitus de las poblaciones. Si este trabajo se centra en los tikuna es porque han integrado tales proposiciones; sin embargo, hoy en día, miembros de grupos vecinos (indígenas como mestizos) adhieren o participan de configuraciones cercanas, hasta optar por la creación de neocomunidades con orientaciones religiosas similares. Entre los tikuna, la posición y la postura de los profetas recuerda, por un lado, la de los narradores tradicionales, y por otro, la de los chamanes. Los primeros restituyen la palabra de los mitos en relación con el origen; los segundos son intermediarios y cuentan lo dicho por las entidades a los humanos. Pero, en cualquiera de los casos -el chamanismo, la narración mitológica o los movimientos proféticos-, se habla siempre de la misma relación entre los mortales, yunatü, y los inmortales, ü-üne. Unos como otros transmiten lo dicho por sus mandantes en cuanto a la gestión del cosmos, y el profeta tiene la voluntad de hacer coincidir lo que les pertenece al chamán y al narrador tradicional con lo suyo. Y más todavía los acerca el hecho de que sus posturas - la del profeta, la del chamán y la del narrador tradicional- se inscriben en la horizontalidad, es decir, en que todos proponen que la salvación se relaciona con convivir en esta tierra na-ane. $\mathrm{Al}$ mismo tiempo, el profetismo no es soluble en una sociedad sin la presencia de una u otra manera del chamanismo, al punto que su copresencia podría ser necesaria para que el primero subsista. En todo caso, hay que prestarles atención a los préstamos recíprocos. 
$p$ ara asegurar su éxito, los profetas deben usar estrategias que les permitan aprovechar momentos de cierta tensión en el interior de una sociedad. Una de estas estrategias es convivir con la gente, otra es lograr que la correspondencia entre la oferta y la demanda sea percibida de modo simétrico. En efecto, muchos de estos movimientos han surgido en periodos conflictivos, en tiempos de insatisfacciones posteriores a cambios notables en el medio ambiente y/o con la intrusión de personas externas que imponen sus modelos de explotación que demandan mano de obra indígena — por ejemplo, el periodo del caucho, entre 1880 y 1920 - Otros aparecieron en momentos de incertidumbre política, como de redefinición de las fronteras — conflicto colomboperuano, entre los años 1920 y 1930—, o económica, como la intensificación de las economías extractivas (madera, pieles, etc.). Los movimientos proféticos surgidos en estas circunstancias pueden ser calificados como endógenos, en la medida en que fueron suscitados por miembros del mismo grupo étnico. Y revisando nuevamente la historia de este fenómeno en la región vemos que los cinco últimos movimientos están relacionados con la llegada de olas masivas de migrantes, que se corresponden con los periodos de prosperidad económica, llamados bonanzas. En este caso, han sido fundamentalmente personas de origen mestizo quienes han introducido estructuras político-administrativas ajenas y han impulsado, al mismo tiempo, modos de relacionarse desconocidos para los indígenas.

Por lo ya dicho, no sorprende que el mensaje de los profetas esté cargado, cada vez más, de préstamos o marcas del mundo de los blancos, como una primera inscripción en algo más abierto al exterior, antes de la "globalidad" que se encuentra en los movimientos Ix y x. Tal situación ha sido posible tras la apertura del medio Amazonas, la cual ha favorecido una aceleración de los intercambios e interferencias (económicos, culturales, simbólicos, etc.) entre las sociedades que se encuentran en este espacio, un fenómeno, por lo demás, que tiene lugar en una escala notablemente amplia en el continente. Otra consecuencia es que el mensaje ha comenzado a dirigirse a poblaciones vecinas, indígenas o mestizas, con quienes los tikuna conviven en la región. Este fenómeno ha caracterizado los últimos movimientos, que deben ser vistos como exógenos por contraste con los anteriores. 
Otra forma de caracterizar estos movimientos consiste en que los primeros han sido de tipo centrífugo, es decir que sus adeptos se han agregado en el interfluvio (espacio de repliegue), mientras que los siguientes lo han hecho de modo centrípeto, reagrupando a sus discípulos en las riberas del río Amazonas (espacio de apertura). No obstante, en ambos contextos, su consecuencia ha sido una redistribución espacial de la población, condición necesaria para el éxito de las propuestas de los profetas.

Finalmente, es preciso añadir que los líderes de los últimos movimientos han negociado para anclar su mensaje, a fin de facilitar la aceptación de sus propuestas. El pastor norteamericano que se instaló en la década de 1950 en una comunidad tikuna del territorio brasileño fue expulsado unos años más tarde por no haber respetado sus obligaciones con sus anfitriones. Retirado a la parte peruana, adonde lo acompañaron sus principales fieles, debió hacer ciertas concesiones, contra su voluntad, para poder instalarse en este territorio. Debido a la reivindicación de la población tuvo que aceptar la permanencia del sistema clánico tikuna, fundamento de las relaciones sociales y de las alianzas matrimoniales de este pueblo. En consecuencia, él y su esposa fueron integrados en un clan diferente cada uno, según la regla de la exogamia de mitades. De igual manera, José da Cruz fue vinculado al clan de los gemelos míticos (Goulard, 2009). No obstante, la estabilidad de la vinculación a un movimiento religioso es variable; de hecho, en el transcurso de una de las ausencias del pastor norteamericano sus discípulos adoptaron el rito pentecostal en vez del rito adventista que él había promovido. Se decía que el rito pentecostal era dinámico, en el sentido de que suscitaba más alegría entre los participantes que el otro.

\section{EL MENSAJe}

- l profeta sustenta un mensaje, definido en la lengua de este - pueblo como ore, es decir, una Palabra que no se puede contra-decir, ni tampoco cuestionar, salvo para crear una disidencia, como sucedió en el caso del movimiento crucista después de la muerte del profeta. El término ore se diferencia de otros del campo semántico tikuna, todos referidos a la palabra: ga hace referencia al tiempo presente, incluido el pasado inmediato, 
para significar, por ejemplo, el "día de la palabra de la púber", woreküchiga; y dea vale para los intercambios verbales de la vida cotidiana. Sin embargo, le prestaremos más atención al término ore por ser la palabra de la oralidad, la de los relatos mitológicos, y al mismo tiempo la del papel popera, de lo escrito en relación a lo contenido en la Biblia y en su traducción a la lengua tikuna.

El ore mitológico es dicho en ciertas condiciones: solamente se pronuncia dentro de la maloka y al final del día. A pedido de unos, mujeres principalmente, y en presencia de niños, empieza un relato en interacción, siempre en contrapunto con las preguntas de los oyentes. El narrador tradicional, "el que sabe

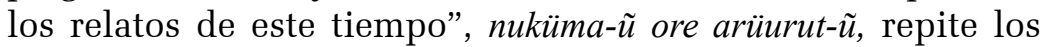
lineamientos de la creación del na-ane y la explicación de los lugares que les fueron asignados a los seres que hoy se conocen. Sin ser canónico, este ore restituye un conocimiento memorizado, heredado de padre a hijo y contado con intervalos regulares a personas que conocen ya la trama y sus principales elementos. Su contenido se encuentra, de manera metafórica, en los cantos que se entonan durante los rituales.

El ore profético es un discurso más dogmático que el anterior, en la medida en que es fijo, estático, dado que se encuentra contenido en el papel popera. No conoce variaciones: la Palabra es asentada por la lectura en la iglesia o en el templo, varias veces a la semana. Se la comenta y se acompaña con cantos. El pastor es el que "transmite la Palabra", ore arüauru-ũ, y es el "guardián de la Palabra", ore daru-ũ.

En ambos casos se trata de un discurso normativo con variantes (mitología) o que puede ser manipulado (evangelio). Para tomar un ejemplo, en la transcripción de la Biblia, realizada por el pastor norteamericano con la ayuda de colaboradores indígenas, la frase "mi palabra es espíritu y es vida" es traducida por charü de-a rüna-a-e ni-i rüochimaũ ni-i, o sea, literalmente, "mi palabra (cotidiana) es mi principio de vida y mi principio corporal" ${ }^{11}$.

11 Para los tikuna cada ser vivo, du-ũ (humano, animal, vegetal, espíritu), posee un principio energético, pora, un principio corporal, ma-ũ, y un principio vital, $a-e$. Con el uso del término de- $a$, los traductores han juntado el principio corporal ma-ũ y el principio vital $a-e$, y de esta manera le dan una inflexión espiritual al primero, lo que no es de ninguna manera el caso en condiciones tradicionales. Los hechos y las actuaciones de cada uno en su 
vida ordinaria son de esta manera incluidos en su búsqueda del Ser, lo que induce una percepción otra de la "persona". Pero, al final, su restitución y su función se asemejan a las del narrador cuando recuerda, a través la palabra mitológica, el proyecto de acceder a la inmortalidad.

Entonces, el mensaje de los movimientos proféticos trata de la salvación e insiste en las condiciones necesarias para alcanzarla. En esto no se diferencia de la palabra mitológica, la cual repite el origen de la gente y no deja de preguntar por qué los tikuna son mortales. Con su restitución, el narrador propone las condiciones para dejar este estado y la perspectiva de cada oyente, creyente o no, queda orientada hacia lo mismo. Se puede pensar entonces que el discípulo de una u otra neorreligión usa el mismo esquema para poseer el

12 Hoy en día los tikuna han empezado un trabajo de recuperación cultural. Me refiero particularmente al caso de un conjunto de jóvenes profesores y de ancianos que, con el apoyo de ciertas ONG, trabajan para restituir sus conocimientos, tanto de la mitología como de prácticas culturales hoy abandonadas. conocimiento inicial, o al menos sus lineamientos principales ${ }^{12}$.

El candidato a uno u otro movimiento adhiere a partir de un fondo común compartido con la gran mayoría de los de su grupo étnico. En consecuencia, la construcción social sigue siendo conforme a la de los relatos, aunque nuevos filtros se han introducido en el marco del contacto con el mundo exterior. En este contexto, creyentes o no, indígenas o no, pertenecen a la misma generación.

In fine, el objetivo de los rituales entre los tikuna es la recuperación de este estado perdido, aunque los que han acompañado al mayor de los gemelos míticos lo poseen todavía: se dice que ellos viven Amazonas abajo, en un territorio limítrofe con el de los tikuna. Mortales e inmortales se inscriben entonces, en términos de espacio, en territorios contiguos cuya separación tendrá que desaparecer una vez que los mortales se reapropien de la inmortalidad. Sin embargo, las condiciones de esta fusión no han sido aún satisfechas, pese a que hay tentativas individuales para acercarse al espacio de los inmortales. Incluso se dice que algunos han podido ubicar esta tierra y hasta han logrado escuchar a los que viven en ella, pero ninguno ha podido entrar en contacto con tales entidades inmortales a causa del estado de impureza de su principio vital.

Por lo anterior, la ejecución reiterada de los rituales demuestra la voluntad permanente y colectiva de acceder a este estado. 
Este es el fin que los participantes esperan alcanzar durante sus rituales, y en ciertas circunstancias la presencia de los inmortales bajo máscaras o en forma de espíritus los ayuda. La relación así establecida es la prueba de que esta opción es la buena. Esto se nota en los rituales tradicionales en los que se usan máscaras, como entre los crucistas y evangelistas cuando el Espíritu Santo se manifiesta en una o más personas. En este último caso, la palabra de la divinidad se encarna en quien la recibe, que pasa a ser su portavoz y anuncia el fin del mundo al mismo tiempo que propone los medios para prevenirlo.

Para cumplir con este idéel, la palabra, sea bíblica o mitológica, impone normas de conducta compartidas por todos los adherentes de los movimientos. Una exige el reagrupamiento de los discípulos en lugares escogidos por el profeta o propuestos a través del mensaje. Después de reconocer el lugar elegido, empiezan la construcción de una casa colectiva, de un templo o de una iglesia. Luego preparan y cultivan juntos una parcela colectiva cuya producción será aprovechada por todos los miembros de la colectividad. Esta secuencia de acciones es similar a la construcción de una maloka en el contexto tradicional, la cual empieza por la disposición de un espacio común dividido en lotes, en el cual cada mujer gestiona el suyo; posteriormente construyen la casa colectiva, lo cual sucede una vez que el cultivo está en producción.

Dentro de la iglesia o del templo, la maloka del movimiento (VIII a x), los creyentes se ciñen a ciertas normas, como la separación entre hombres y mujeres, y la conducta del ritual va exclusivamente de la mano de un hombre. Además, en su vida cotidiana no pueden tomar bebidas alcohólicas ni fumar (viII y Ix). Al mismo tiempo, no solo se conforman con las reglas de la organización social vistas arriba, sino que las alianzas matrimoniales se realizan únicamente entre miembros del mismo movimiento, lo que añade un aspecto segregativo con la introducción de un parentesco espiritual. Como consecuencia de esta conformidad, los lugares elegidos serán salvados cuando llegue el próximo cataclismo, diluvio o incendio, cuyas modalidades son ya conocidas a través de la palabra mitológica y bíblica. En cuanto a los otros, los no convertidos, son condenados a desaparecer con la catástrofe. Esta situación es simétrica a la del contexto tradicional: ya se ha hablado del incesto, y se dice en los relatos mitológicos que aquellos que habían consumido la carne de un 
ser ü-üne asesinado por inconsciencia tuvieron que morir; los pocos que no, por el contrario, sobrevivieron.

Finalmente, el contexto y los modos de actuación, en la situación tradicional ${ }^{13} \mathrm{y}$ en la neorreligiosa, conocen un proceso

13 Para los tikuna la tradición se refiere también al mundo católico, y es opuesta a los discursos de los movimientos religiosos mencionados, los cuales conllevan la idea de civilización, otro término de la modernidad. semejante. En ambos, es importante que esté presente el máximo posible de personas en la celebración de cada ritual. Esta exigencia es explícita, e incluye

a los vecinos mestizos. Una asistencia masiva determina el éxito del evento y favorece la relación con las entidades o la deidad. Además, por su "alteridad", los invitados podrán testificar del éxito de la celebración.

Entonces, el mensaje de los movimientos recupera el esquema del ore de los relatos mitológicos. Hoy en día, la aceptación de uno u otro de los profetas presenta gran interés para la mayoría de los tikuna, por aportar una palabra confirmada por lo escrito. La reflexión de un informante resume la contemporaneidad de esta "palabra del papel": él mismo asegura que podría aceptar el relato de Joi e Ipi, los gemelos míticos, si existiera en forma escrita, pero hoy solamente Tupana tiene el suyo en la Biblia.

\section{LA ADHESIÓN}

$n$ la actualidad hay siempre candidatos para integrar uno u otro

- movimiento, pero las condiciones para adherirse han cambiado. Los últimos movimientos agrupan a un número importante de personas, lo que no sucedió en los primeros, por haber tenido un impacto principalmente local. Además, los medios de comunicación eran menos decisivos y la población indígena, menos numerosa. Estos movimientos eran propios de un área limitada; hoy, por el contrario, se han extendido e incluyen la vecindad, mestiza y/o indígena.

En los últimos movimientos, los primeros seguidores de un profeta entraron por "derecho" y ocuparon las principales funciones. El encuentro inicial es percibido como un reconocimiento que da un certificado de validez, como si la anterioridad otorgara la primacía. Así, en el movimiento crucista (viII), los habitantes de las quebradas o del interfluvio que fueron a esperar al Hermano 
durante su descenso del río Amazonas ganaron un aura que los hizo entrar en el grupo de los "escogidos". Después, investidos de la representación del profeta, ocuparon los principales cargos en su comunidad. Un fenómeno similar tuvo lugar entre las primeras familias que siguieron al cura católico del movimiento $\mathrm{x}$, quienes ocuparon una posición privilegiada frente a las que llegaron posteriormente.

Si el neoagrupamiento ha sido la regla, la multiplicación de los candidatos necesitó adaptar esta obligación a fin de mantener la cohesión del proyecto. El movimiento crucista ha favorecido la creación de neocomunidades; estas aparecen a partir del momento en que se acepta su adhesión al movimiento y se concentran siempre alrededor de una cruz bendecida por el profeta. Pero al mismo tiempo conservan la presencia de un delegado en la jerarquía local impuesta, aunque se mantenga el centralismo propio del movimiento, lo que, con el tiempo, ha motivado el desinterés entre muchos.

El sistema evangelista, por su parte, actuó de manera diferente, creando comunidades autónomas que no reconocen entre ellas ninguna pertenencia común ni tampoco coordinación alguna: son autónomas hasta reivindicarse como pertenecientes a iglesias diferentes ${ }^{14}$. En ambos casos, crucistas y evangelistas celebran cada año su fundación, asociándola con un evento interno: una visión, la expulsión del último comerciante

14 Con esta conducta, cada comunidad constituye un movimiento diferenciado de los demás, bien sea que se afilie a la Iglesia coreana, a la suiza, a la panamericana, etc.; hay que entenderlo ante todo a través de la financiación del sueldo de los pastores y de las obras que se realizan en las comunidades.

blanco o la bendición de la cruz por el profeta, entre otros hechos destacados.

El asentamiento iniciado con una o más familias recibe poco a poco a candidatos que desean residir en él, pero son aceptados solo los que están de acuerdo con someterse a las reglas existentes. Un elemento que facilita el proceso es que frecuentemente los postulantes hacen parte de la parentela de aquellos ya instalados en la neocomunidad. Sin embargo, las reglas de distribución del espacio en los nuevos asentamientos religiosos tienden a retomar un modelo indígena ya conocido, el del área local que incluye cuatro o cinco malokas (Goulard, 2009). El área local define los límites de los intercambios, al mismo tiempo que los contiene, tanto en lo económico (autosuficiencia alimentaria) como en lo 
La metamorfosis ritual: la identidad religiosa en la Amazonia

ritual y en las alianzas matrimoniales. En los nuevos pueblos prevalece el reagrupamiento de la gente en barrios clánicos, y las alianzas matrimoniales se reali-

15 Tales proporciones derivan de estudios genealógicos realizados por el autor con una población de cerca de 4.000 personas entre 1988 y 1990, incluida una comunidad compuesta por más de 2.000 personas en la que se realizan más del $90 \%$ de las alianzas intramuros. zan en la misma área poblacional; de hecho, se trata de más del $90 \%$ en un pueblo evangelista y de más del $60 \%$ en otros lugares ${ }^{15}$ estudiados.

Si la adhesión por proximidad es compartida por los movimientos, esta opción no es suficiente en los tres últimos, en los que aquellos que van a ocupar cargos tienen que completar su iniciación. Aunque los primeros discípulos figuran entre los escogidos, percibidos como los que han recibido una delegación del profeta, ellos mismos han tenido que confirmar sus capacidades con una formación complementaria. Si su lugar está asegurado de facto por su relación específica, ellos tienen que corroborarla. Es preciso que pasen temporadas en sitios especiales: los del movimiento crucista (viII) visitan de manera regular a Vila Alterosa (Brasil), donde se estableció el profeta después de su recorrido por el río Amazonas; los del movimiento evangelista (IX) residen por periodos en la base-sede situada en el piedemonte andino peruano, donde está reagrupado el conjunto de evangelistas del país; y los del movimiento católico (x) viajan a la sede de la orden religiosa del fundador, en Bogotá, donde completan sus conocimientos religiosos y al mismo tiempo prueban una relación directa y privilegiada con el mundo de los blancos, aspecto de gran importancia, como veremos más adelante.

La elección de estos primi inter pares tiene ciertas consecuencias. Así, en el movimiento ix los primeros fueron dos hermanos y uno de sus cuñados, que siguieron desde el Brasil al pastor norteamericano, quien completó su grupo básico con otros que reclutó: fue a buscar a uno más en Lima, ciudad donde se había quedado después de su servicio militar, a otro en los suburbios de Iquitos, dado que trabajaba en un barco de mercancías en el río Amazonas, etc. La elección de estos últimos puede entenderse por el conocimiento que habían adquirido en su convivencia con los blancos, convivencia que en este contexto tiene un valor iniciático. Sus diferentes experiencias complementaban las de los primeros discípulos que habían convivido desde el comienzo con el pastor. Pero, para “entrar en religión”, tuvieron que enfrentar 
pruebas, entre ellas separarse de los suyos. Este periodo ha sido considerado por todos los entrevistados como una prueba de sufrimiento necesaria, que es aceptada en aras del papel que se cumplirá en la comunidad como pastor o profesor. Además, todos aquellos que ocuparon los principales cargos pertenecían a tres clanes e iniciaron un sistema de herencia de sus puestos, y así, cuando se jubilaron, sus hijos los reemplazaron.

Durante el rito de la pubertad las jóvenes tikuna son separadas de los suyos. Conocen un periodo de aislamiento, de hasta varios meses, y reciben la visita exclusiva de sus madres y de algunas tías que las aconsejan. Es un momento de formación antes de integrarse al mundo de los adultos. En cuanto a los jóvenes, al terminar su proceso de iniciación acompañan a su padre en sus actividades, y entre otras cosas, aprenden los secretos de la cacería y del monte. Por su parte, después de la celebración de su ritual de iniciación, las jóvenes se quedan cerca de su madre, quien les enseña los oficios de la casa. Un análisis de lo que se deriva de la educación escolar autoriza a pensar que esta ocupa un papel similar de aislamiento, de un corte en su proceso de adquisición de los principios culturales. Así, los que estaban escolarizados en el nivel de secundaria hasta hace poco han vivido en internados ${ }^{16}$, separados de sus familias durante largos periodos para recibir al final de sus estudios un diploma que atestigua su formación, proceso que se emparenta con una iniciación ${ }^{17}$. Por su lado, los de ambos sexos que no han estudiado pueden pasar un periodo, de un año o más, fuera de su comunidad, trabajando para un patrón blanco (en negocios, agricultura u otras actividades), lo que se entiende igualmente como un proceso iniciático.

Estos periodos son considerados como de aprendizaje, a veces doloroso, y constituyen un

16 En la primera década del presente siglo se establecieron colegios de secundaria en los caseríos tikuna, en los más poblados del Brasil y del Perú.

17 Se está introduciendo de nuevo el ritual de la pubertad femenina en algunas comunidades que se reivindican con respecto a uno de los tres últimos movimientos, en las que había sido abandonado, despreciado e incluso prohibido. Se celebra con las jóvenes en el periodo de vacaciones escolares. En ciertos casos, se junta con la celebración de los quince años prestada del mundo ibérico: resulta un ritual reivindicado como propio, que une lo étnico y lo prestado. Se debe notar que, en este contexto, se atrasa la edad del paso a la clase adulta. "entre-dos" que autoriza enseguida a conseguir esposo o esposa, lo mismo que en la situación tradicional. Al tiempo, la separación exigida hace parte de una trayectoria necesaria para que los iniciados se consideren completos o cumplidos. 
A pesar de lo anterior, tales pruebas revisten una gran exigencia para los iniciados. ¿Qué candidato no ha querido escaparse del internado para volver con los suyos? Las penurias son muchas, pero en esta sociedad se gana prestigio por haber compartido el mundo de los blancos, dado que de ellos se aprenden "secretos" (modos de vivir, acceso a las máquinas, etc.) que pueden representar beneficios para la comunidad. Es un sacrificio comparable con el del aprendiz de chamán, quien convive todo el tiempo con su maestro, privándose de tener relaciones sexuales para purificar el cuerpo y así someterse a otras obligaciones.

Hoy en día, cualquiera que sea el camino escogido por cada uno, el modo de adhesión está siempre asociado con las visiones que se experimentan hasta antes de entrar en un movimiento. Es necesario que Joi, Ipi, Ngutapa, Tupana o Dios se hayan manifestado, en el sueño o durante la celebración de un ritual. Esto vale en los tres últimos movimientos, en los cuales una primera visión es un criterio necesario para una adhesión, y si esta es seguida por otras se confirma la elección. En verdad, para que sea efectiva, cada uno necesita establecer una relación directa con la entidad. De nuevo, esta situación presenta similitudes con el recorrido del aprendiz de chamán, quien al estar en contacto con los espíritus auxiliares del chamán que lo ha sanado aumenta sus capacidades y le resulta más fácil adquirir conocimientos y superar el periodo de formación.

No solo los que ocupan un puesto (pastor, profesor, promotor de salud, etc.) pueden tener visiones, pues sucede igual con otros miembros de la comunidad. En el transcurso de un ritual religioso, un hombre o una mujer pueden tener una visión, lo

18 Es el mismo término para el soplo del cazador cuando usa su cerbatana y para el soplo del chamán cuando cura a un enfermo. que atestigua que poseen un don, literalmente, un soplo, fue ${ }^{18}$. Por ejemplo, en una celebración a la cual asistí, una mujer "vio"

la conducta incestuosa del pastor indígena de la comunidad y la expuso ante los presentes, con el resultado de que este último fue destituido de inmediato de su puesto y reemplazado por otro que tenía la formación adecuada. La visión de esta mujer sirvió como testimonio de que había sido escogida por la deidad para hacer la denuncia. Entonces, gracias a la visión, una persona sin estatuto específico en la gestión del movimiento se hizo reguladora de la vida colectiva. En el movimiento crucista fue el profeta 
mismo, José da Cruz, quien denunció la conducta incestuosa de una mujer que reivindicaba ser discípula suya. Recordemos que algunos de los primeros movimientos proféticos entre los tikuna, iniciados por chamanes, fracasaron tras la denuncia de sus conductas incestuosas.

Todos los actores de estos últimos movimientos de los cuales se ha hablado están presentes hoy en día en la escena tikuna, lo que no ha hecho desaparecer algunas ambigüedades. Así, se mantiene una lucha sorda entre los chamanes en actividad y los que ocupan puestos de carácter religioso. Esta competencia se manifiesta de forma evidente en lo relativo a la enfermedad, que tanto los promotores de salud como los pastores y los chamanes gestionan con muchas prevenciones. Según el diagnóstico, cada uno le presenta al que consulta la posibilidad de escoger entre una cura bíblica, una chamánica o una occidental, con un médico. Es una manera tácita de compartir un principio de precaución para evitar toda reacción en contra del que sana en caso de fracaso. Aunque se le indique una cura con el chamán o el promotor de salud, la persona enferma puede dirigirse al pastor, pero, de manera general, se combina algo de cada uno, según la gravedad de la enfermedad. En todo caso, hay una enfermedad, o por lo menos considerada como tal, que es la envidia, que nadie sabe curar y termina muchas veces con la muerte por no haber sido diagnosticada. Finalmente, la perpetuación de la sociedad étnica necesita una gestión equilibrada de las relaciones entre los mortales, y entre ellos y la deidad o la entidad, cualquiera que sea la adhesión de cada uno.

\section{¿EN ESPERA DE UN CICLO NUEVO?}

$\int_{\mathrm{t}}^{\mathrm{e}}$ acuerdo con la propuesta de Izard $(2002,604)$, sería "profetismo todo discurso que se da por la palabra de Dios. [Sería] mesianismo la forma particular del profetismo dedicada al anuncio de la llegada de un enviado por Dios", y agregamos, la de Dios mismo. Además, el profetismo contendría "una palabra secular", cuando la del mesianismo sería "una palabra escatológica" (604). Pero, como se ha visto, entre los tikuna es siempre la misma palabra la que prevalece, ya sea oral o escrita, la secular y la escatológica están ahí reunidas. 
En todo caso, al terminar esta exposición de los diferentes aspectos de la creencia religiosa entre los tikuna es importante preguntarse sobre la permanencia o no de referentes que, de una forma u otra, serían compartidos y reivindicados por todos los miembros del grupo étnico. Adherir a un movimiento sería finalmente perpetuarse de un modo reflexivo, porque siempre perdura un mismo conocimiento, lo que demuestra la proclividad de los tikuna a renovarse, y entonces se puede hablar de metamorfosis ritual.

Por otro lado, no se trata tanto de un sincretismo sino de una construcción permanente del Sí étnico que se perpetúa hoy con el popera, sacralizado por la adopción de la escritura, portadora de categorías de pensamiento (Benveniste, en Babadzan 1985, 117), tal y como ha sido valorada la oralidad por los narradores. Adoptando esta perspectiva, los tikuna no se inscriben en la discriminación de un pasado, sino en una perspectiva moderna, respetando la misma relación con el universo.

Se entiende mejor que los de la generación actual, cualquiera que sea la adhesión que privilegien, viven en una tierra considerada como vieja, y que, por eso, se acerca cada día al próximo cataclismo. Luego de tal catástrofe la generación actual será reemplazada por una nueva, constituida por los que se hayan protegido, es decir, aquellos que hayan seguido las reglas enunciadas por el ore. Es lo que los últimos narradores no dejan de recordar en sus relatos, para incentivar la recuperación de ciertas prácticas, como el ritual de la pubertad femenina.

La palabra bíblica no es diferente de la mitológica que retoma los mismos consejos. En este contexto, si el fin del ciclo es temido por muchos, el ideal postula que los cuadros propuestos ofrezcan perspectivas similares, hasta por el uso de los mismos términos. En ambos casos, la separación entre mortales e inmortales tendría que desaparecer para que se forme una sola humanidad que se beneficiará del estado de inmortalidad, ya sea la propuesta formulada por los gemelos míticos y/o aquella predicada por los profetas, facilitada por la permanencia de unas invariantes culturales. 


\section{REFERENCIAS}

BabadZAn, Alain. 2003. “Syncrétisme religieux, identités politiques”. En Insularités. Hommage à Henri Lavondès, editado por Alain Babadzan, 167-177. Nanterre: Société d'Ethnologie.

Godelier, Maurice. 2007. Au fondement des sociétés humaines. París: Albin Michel.

Goulard, JeAn-Pierre. 2009. De mortales a inmortales. El Ser en el mundo tikuna de la Amazonia. Lima: Institut Français d'Etudes Andines Centro Amazónico de Antropología y Aplicación Práctica

Goulard, Jean-Pierre y Maria Emilia Montes. 2012. "Los yurí/juri-tikuna, en el complejo sociolingüístico del noroeste amazónico". Mundo Amazónico, revista del Instituto Amazónico de Investigaciones, Universidad Nacional de Colombia, sede Amazonia. Manuscrito aceptado para publicación.

IzARD, MiCHel. 1991/2002. "Prophétisme”. En Dictionnaire de l"ethnologie et de l'anthropologie, editado por Michel Izard y Pierre Bonte, 603605. París: Presses Universitaires de France.

MÉTRAux, Alfred. 1928. La religion des Tupinamba et ses rapports avec celle des autres tribus Tupi-Guarani. París: Ernest Leroux.

Nimuendaju, Curt. 1952. The Tukuna. Berkeley: University of California Press.

Oro, Ari Pedro. 1985. "Un mouvement messianique actuel en Amazonie brésilienne: la Fraternité de la Sainte-Croix”. Tesis de doctorado, Université de la Sorbonne Nouvelle-Paris III, París.

Oro, Ari Pedro. 1989. Na Amazônia um Messias de indios e brancos. Traços para uma antropologia do messianismo. Petrópolis y Porto Alegre: Vozes y Edipucrs.

SAntos Angarita, Abel. 2005. "Hacia una dialectología tikuna del trapecio amazónico colombiano”. Tesis de pregrado, Universidad Nacional de Colombia, Sede Leticia.

Vinhas DE Queiroz, Mauricio. 1963. “Cargo-cult na Amazonia. Observaçoes sobre o milenarismo Tukuna”. America Latina 6-4: 43-61.

Wright, RoBIN. 1992. "História indígena do Noroeste da Amazônia. Hipóteses, questôes e perspectivas”. En História dos índios no Brasil, editado por M. Carneiro da Cunha, 253-266. San Pablo: Compahia das Letras.

Wright, RoBIn, ed. 2004. Transformando os Deuses. Igrejas evangélicas, pentecostais e neopentecostais entre os povos indígenas no Brasil, vol. II. Campinas: Unicamp. 